\title{
No evidence for interstitial lung oedema by extensive pulmonary function testing
} at $4,559 \mathrm{~m}$

\author{
C. Dehnert*, A.M. Luks* ${ }^{\#}$, G. Schendler*, E. Menold*, M.M. Berger", \\ H. Mairbäurl*, V. Faoro ${ }^{+}$, D.M. Bailey ${ }^{\S}$, C. Castell*, G. Hahn ${ }^{\dagger}$, P. Vock**, \\ E.R. Swenson" and P. Bärtsch*
}

ABSTRACT: The aim of the present study was to better understand previously reported changes in lung function at high altitude.

Comprehensive pulmonary function testing utilising body plethysmography and assessment of changes in closing volume were carried out at sea level and repeatedly over 2 days at high altitude $(4,559 \mathrm{~m})$ in 34 mountaineers.

In subjects without high-altitude pulmonary oedema (HAPE), there was no significant difference in total lung capacity, forced vital capacity, closing volume and lung compliance between low and high altitude, whereas lung diffusing capacity for carbon monoxide increased at high altitude. Bronchoconstriction at high altitude could be excluded as the cause of changes in closing volume because there was no difference in airway resistance and bronchodilator responsiveness to salbutamol. There were no significant differences in these parameters between mountaineers with and without acute mountain sickness. Mild alveolar oedema on radiographs in HAPE was associated only with minor decreases in forced vital capacity, diffusing capacity and lung compliance and minor increases in closing volume.

Comprehensive lung function testing provided no evidence of interstitial pulmonary oedema in mountaineers without HAPE during the first 2 days at 4,559 $\mathrm{m}$. Data obtained in mountaineers with early mild HAPE suggest that these methods may not be sensitive enough for the detection of interstitial pulmonary fluid accumulation.

KEYWORDS: Body plethysmography, closing volume, high altitude, hypoxia, pulmonary oedema

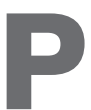

revious investigations reported reduced forced vital capacity (FVC) [1-12] and reduced forced expiratory volume in $1 \mathrm{~s}$ (FEV1) $[3,7,9,10,12]$, as well as increased closing volume (CV) $[4,12,13]$, during the first days after ascent to altitudes of $2,800-5,300 \mathrm{~m}$. These findings were interpreted as being consistent with pulmonary interstitial fluid accumulation or subclinical high-altitude pulmonary oedema (HAPE). However, there are several other factors that could also account for or contribute to the observed changes.

Prolonged and intense exercise, even at low altitude, can lead to an increase in pulmonary interstitial fluid accumulation [14-16], suggesting that the physical effort of mountaineering may cause a transient increase in pulmonary interstitial fluid independent of the effects of altitude. Bronchoconstriction during or following exercise in a cold and dry environment [17-19] occurs frequently, even in asymptomatic athletes, and may account for the increased CV. Furthermore, hypocapnia due to hypoxia-induced hyperventilation can cause mild peripheral bronchoconstriction [20]. Pulmonary function testing can also be affected by fatigue or the debilitating symptoms of acute mountain sickness (AMS), which may impair the maximum effort critical to adequate pulmonary function testing and interpretation.

In an effort to gain better insight into previously reported changes in lung function, a comprehensive programme of pulmonary function testing was conducted using body plethysmography at sea-level and following rapid ascent to $4,559 \mathrm{~m}$, and included measurements of lung volumes, lung diffusion capacity for carbon monoxide $(D L, C O), C V$, lung compliance and airway resistance (effective (Reff) and total specific airway resistance (sRaw)), spirometry and assessment of bronchodilator responsiveness. If extravascular

\section{AFFILIATIONS}

*Internal Medicine VII, Sports Medicine, University Hospital Heidelberg,

'Dept of Anaesthesiology, University Hospital Heidelberg, Heidelberg,

${ }^{f}$ Dept of Anesthesiological Research, University of Göttingen, Göttingen, Germany,

\#Division of Pulmonary and Critical Care Medicine, University of Washington, Seattle, WA, USA, ${ }^{+}$Dept of Pathophysiology, University of Brussels, Brussels, Belgium, ${ }^{\S}$ Dept of Physiology, University of Glamorgan, Pontypridd, UK, and ${ }^{* *}$ Dept of Radiology, University Hospital Inselspital, Berne, Switzerland.

\section{CORRESPONDENCE}

C. Dehnert

Medical Clinic, Internal Medicine VII, Sports Medicine

University Hospital Heidelberg

Im Neuenheimer Feld 410

69120 Heidelberg

Germany

E-mail: christoph.dehnert@med.

uni-heidelberg.de

Received:

Dec 082008

Accepted after revision:

Sept 182009

First published online:

Oct 192009

European Respiratory Journal

Print ISSN 0903-1936

Online ISSN 1399-3003 
lung water accumulates to the extent proposed by these prior studies, it would be expected that there would be evidence of decreased vital capacity, decreased airflow, impaired DL,CO/ alveolar volume (VA), decreased lung compliance and increased CV. Since AMS is associated with fluid retention [21] and worsened gas exchange [22], pulmonary interstitial fluid accumulation might be more pronounced in subjects with AMS. Subjects with known susceptibility to HAPE were also included as controls for measurements of these parameters in patients with clinically evident pulmonary oedema.

\section{METHODS}

\section{Study population}

The present study was performed according to the Declaration of Helsinki and its current amendments, and was approved by the Ethics Committee of the Medical Faculty of the University of Heidelberg (Heidelberg, Germany). A total of 38 healthy non-acclimatised subjects living at low altitude (32 males and six females) were included after providing written informed consent. Of the 38 subjects enrolled in the study, four withdrew prior to ascent to high altitude and their data is not included in the analysis. Therefore, the analysis is based on the 34 subjects (five females) who completed all of the low- and high-altitude testing sessions (mean \pm SD age $37 \pm 10 \mathrm{yrs}$, height $178 \pm 9 \mathrm{~cm}$ and body weight $77 \pm 10 \mathrm{~kg}$ ). Of those ascending to high altitude, 30 subjects had been above 3,000 m several times, 16 were considered well-trained and experienced mountaineers, eight developed symptoms of AMS frequently, six were considered HAPE-susceptible because of at least one previous episode of HAPE and three had participated in previous studies at the Capanna Regina Margherita. The mean maximal oxygen uptake assessed using a bicycle ergometer in a ramp test starting at $50 \mathrm{~W}$ and increasing at $25 \mathrm{~W} \cdot \mathrm{min}^{-1}$ was $52 \pm 9 \mathrm{~mL} \cdot \mathrm{min}^{-1} \cdot \mathrm{kg}^{-1}$, and the maximum workload in this test was $322 \pm 42 \mathrm{~W}$ (or $\left.4.2 \pm 0.8 \mathrm{~W} \cdot \mathrm{kg}^{-1}\right)$.

\section{Study design}

The health status of the subjects was evaluated, and subjects with pulmonary diseases (e.g. asthma) were excluded before the baseline measurements were performed at an altitude of 110 m (Heidelberg, Germany; low-altitude measurement (LA); barometric pressure $(P B)$ ranging $748-758 \mathrm{mmHg})$. After 24 weeks, the subjects climbed from 1,100 to 4,559 m (Capanna Regina Margherita; PB ranging 435-442 mmHg) within $<24 \mathrm{~h}$, with one overnight stay at $3,600 \mathrm{~m}$ (Capanna Giovanni Gnifetti). Study measurements were performed $\sim 4$ (high altitude measurement (HA) 1), 20 (HA2) and $\sim 44 \mathrm{~h}$ (HA3) after arrival at the Capanna Regina Margherita.

AMS or HAPE were treated according to the general recommendations [23]. Subjects with clinical and radiographic signs of HAPE were given nifedipine and supplemental oxygen. Headache was treated with acetaminophen $(500 \mathrm{mg}$ ) or ibuprofen (400 mg). One subject with severe AMS received dexamethasone $(4 \mathrm{mg})$ during the second night at high altitude. Final measurements were performed prior to treatment of HAPE or severe AMS, and the study was terminated thereafter. In addition to the data reported in the present article, studies on the pulmonary circulation [24] and oxidative stress were performed and are being reported separately.

\section{Pulmonary function testing}

Subjects were familiarised with the procedures in a separate session before collection of baseline measurements. Flow and pressure sensors, the chamber of the body plethysmograph and gas analysers were calibrated before each measurement. Tests were performed according to the guidelines of the American Thoracic Society (ATS) for pulmonary function testing [25]. In all measurements performed during normal tidal breathing, respiratory frequency was guided by a metronome set at a frequency of 10 beats $\cdot \mathrm{min}^{-1}$. The sequence of measurements was the same at each time point. Special attention was paid to obtaining maximum effort by constant strenuous and repeated verbal direction.

\section{Spirometry and body plethysmography}

Lung volume, DL,CO, Reff and sRaw measurements were obtained using a standard body plethysmograph equipped with a pneumotachograph (Jäger MasterScreen Body; VIASYS Healthcare, Hoechberg, Germany). Reff, sRaw and intrathoracic gas volume (ITGV) were determined during tidal breathing. At least five typical breathing cycles served for determination of Reff and sRaw. ITGV was measured at least three times. Reported values are the mean of three measurements. Thereafter, an FVC manoeuvre was performed. Measurements were accepted if FVC and peak expiratory flow (PEF) differed by $<200 \mathrm{~mL}$ and $<0.5 \mathrm{~L} \cdot \mathrm{s}^{-1}$, respectively, for three different measurements. The reported values are the maximum of the acceptable measurements. Forced expiratory flows were taken from the trial with the highest sum of FVC and FEV1.

For determination of the alveolar-arterial oxygen tension difference $\left(\mathrm{PA}-\mathrm{a}, \mathrm{O}_{2}\right)$, alveolar oxygen tension $\left(\mathrm{PA}, \mathrm{O}_{2}\right)$ was calculated from the alveolar gas equation:

$$
P A, \mathrm{O}_{2}=F \mathrm{I}, \mathrm{O}_{2}(P \mathrm{~B}-47)-P A, \mathrm{CO}_{2}\left(F \mathrm{I}, \mathrm{O}_{2}+\left(1-F \mathrm{I}, \mathrm{O}_{2}\right) / \mathrm{R}\right)
$$

where $\mathrm{FI}, \mathrm{O}_{2}$ is inspiratory oxygen fraction, $\mathrm{PA}_{1} \mathrm{CO}_{2}$ alveolar carbon dioxide tension and $\mathrm{R}$ respiratory exchange rate. $\mathrm{PA}, \mathrm{CO}_{2}$ was assumed to be equal to the arterial carbon dioxide tension, $\mathrm{R} 0.85$ and body temperature $37.0^{\circ} \mathrm{C}$. The arterial oxygen tension was measured in arterial blood sampled through a radial artery catheter (Rapidlab 840; Bayer Diagnostics, Sudbury, UK) that was also used for another study [24]. At $\mathrm{HA} 3, \mathrm{PA}-\mathrm{a}, \mathrm{O}_{2}$ was calculated from an arterialised capillary (ear lobe) blood sample, since arterial lines were removed at HA2. $D \mathrm{~L}, \mathrm{CO}$ was measured using the single-breath $\mathrm{CO}$ rebreathing method. Values were adjusted to the lower oxygen tension at higher altitude according to the formula given in the guidelines of the ATS/European Respiratory Society [26]:

$$
\text { DL,CO,Alt }=D L, C O /\left(1+0.0031\left(P \mathrm{I}_{2}, \mathrm{Alt}-150\right)\right)
$$

where $D \mathrm{~L}, \mathrm{CO}$ and $\mathrm{DL}, \mathrm{CO}, \mathrm{Alt}$ are the measured single-breath $D \mathrm{~L}, \mathrm{CO}$ and that corrected for altitude, respectively, $\mathrm{P}_{\mathrm{I}, \mathrm{O}_{2}, \text { Alt is }}$ the inspiratory oxygen tension $\left(\mathrm{P}_{1}, \mathrm{O}_{2}\right)$ at altitude and $150 \mathrm{mmHg}$ is the assumed $\mathrm{PI}_{\mathrm{I}} \mathrm{O}_{2}$ at sea level.

\section{Compliance measurement}

Lung compliance was calculated from transpleural pressure differences in relation to volume changes measured using an oesophageal balloon and body plethysmograph, respectively. Dynamic compliance was determined during normal tidal breathing, whereas static compliance was determined at every 
$200 \mathrm{~mL}$ exhaled volume during the first half of a slow vital capacity manoeuvre. Reported values are the mean of at least three measurements.

\section{Closing volume}

$\mathrm{CV}$ was determined according to the single-breath nitrogen washout method as described by WEST [27], using a customdesigned spirometric device (ZAN600; ZAN Messgeräte, Oberthulba, Germany). Briefly, after a single breath of $100 \%$ oxygen taken to total lung capacity (TLC), a slow vital capacity manoeuvre with an exhaled airflow of $\sim 0.5 \mathrm{~L} \cdot \mathrm{s}^{-1}$ was performed. Visual feedback of measured exhalation rate helped the subjects to maintain the airflow within $0.4-0.6 \mathrm{~L} \cdot \mathrm{s}^{-1}$ without superimposing a resistance device. Special care was also taken to achieve complete expiration. Therefore, as the airflow fell below $0.4 \mathrm{~L} \cdot \mathrm{s}^{-1}$, subjects were verbally encouraged to keep exhaling for as long as possible in order to obtain maximum exhalation. The nitrogen concentration during the exhalation was recorded and the onset of airway closure was identified as the point of intersection between the slopes of phase III and IV of the expirogram. The CV was defined as the difference between the onset of airway closure and complete exhalation. The linear fitting of phase III and phase IV was performed in random order by two examiners blinded to the subjects' data. Measurements were only accepted if the difference in $\mathrm{CV}$ between the two examiners was $<100 \mathrm{~mL}$. Three CV measurements (one at LA and two at HA1) and five CVs from the bronchodilation test (one at LA, three at HA2 and one at HA3) had to be excluded. The reported values are the mean of the measurements with an intra-observer difference of $<100 \mathrm{~mL}$.

\section{Diagnosis of HAPE and AMS}

The diagnosis of HAPE was based on chest radiography, as previously described [28]. Daily chest radiography was performed on all subjects, and the radiographs were analysed in random order by a radiologist blinded to the clinical and experimental data. AMS was assessed using the Lake Louise Scoring System [29] and the cerebral symptoms of AMS (AMS-C) score of the Environmental Symptoms Questionnaire [30]. AMS was diagnosed if subjects had a Lake Louise score of $>4$ and an AMS-C score of $\geqslant 0.70$ in the morning of the second day at $4,559 \mathrm{~m}$. If both scores were below these cut-off points, subjects were considered not to have AMS, whereas the diagnosis of AMS was uncertain if one score was above and the other below the cut-off point.

\section{Bronchodilator testing}

In order to test for evidence of bronchoconstriction, body plethysmography and $\mathrm{CV}$ measurements were repeated $10 \mathrm{~min}$ after administration of $200 \mu \mathrm{g}$ salbutamol (two single doses of Sultanol $\mathrm{N}_{\mathbb{}}$ ) by inhalation.

\section{Missing values}

Owing to bad weather, the equipment was not set up completely in time, and, therefore, no data from body plethysmography at HA1 could be obtained in the first three subjects, which included one subject who developed HAPE. In one further subject, body plethysmography did not meet the quality criteria at HA2 (premature termination of exhalation). These results were excluded from the analysis.

\section{Statistics}

A power analysis based on the CV data reported by CREMONA et al. [13] indicated that a group size of 30 would yield a statistical power of 0.80 at a significance level of 0.05 for detecting a difference of $25 \%$ between groups. One-way and two-way repeated-measures ANOVA were performed in order to identify differences between low and high altitude and over time at altitude, as well as between subjects with and without AMS. Post hoc testing was performed using a paired t-test for the effect of time and an unpaired t-test for the effect of group. A p-value of $<0.05$ was considered significant. Statistical analyses were performed using the SigmaStat ${ }_{B}$ software package (SPSS, Inc., Chicago, IL, USA). Statistical analysis was not carried out on the data obtained in subjects with HAPE since there were only four cases.

\section{RESULTS}

A total of 34 subjects ascended to the Capanna Regina Margherita. Of these, 14 subjects developed AMS and 10 had no AMS. In six subjects, the diagnosis of AMS was uncertain since one of the two scores (Lake Louise score or AMS-C score) was below the required criterion score. They were excluded from the comparison between subjects with and without AMS. Four subjects developed HAPE; all others showed no signs of interstitial or alveolar pulmonary oedema on any of their chest radiographs. Their data were analysed separately.

\section{Data from all subjects without HAPE}

The 30 subjects without signs of pulmonary oedema were classified as having no HAPE. Among these subjects without HAPE (table 1), there were no changes in TLC or FVC, expressed either as absolute values or as percentage of the predicted value, between low and high altitude. The mean TLC was $7.6 \pm 1.2 \mathrm{~L}$ at LA and during all measurements at altitude. $\mathrm{CV}$ also did not change $(\mathrm{p}=0.61)$ between low and high altitude and during the $48 \mathrm{~h}$ at altitude. Individual values over the study period are shown in figure 1. There was a nonsignificant increase in static pulmonary compliance between low and high altitude $(p=0.07)$. Inspiratory muscle strength was significantly reduced at high altitude from $11.5 \pm 2.8$ to $10.6 \pm 2.6 \mathrm{kPa}$ $(\mathrm{p}<0.001)$ at HA1 and $10.8 \pm 2.4 \mathrm{kPa}(\mathrm{p}=0.001)$ at HA2. Despite this small reduction in inspiratory muscle strength, maximum voluntary ventilation increased at high versus low altitude by 20 (HA1; p<0.001) and 19\% (HA2; p<0.001), respectively.

FEV1, expressed both as an absolute value and as a percentage of FVC (table 2), as well as PEF (data not shown) and mean expiratory flow between 25 and $75 \%$ of FVC, significantly increased from LA to HA1 ( $\mathrm{p}<0.001$ for each parameter), with a nonsignificant decrease during the stay at altitude. Reff and sRaw during tidal breathing did not change significantly throughout the study.

Arterial oxygen saturation $\left(\mathrm{Sa}_{\mathrm{a}} \mathrm{O}_{2}\right)$ showed the expected decrease at high altitude (table 3). DL,CO/VA increased significantly at high versus low altitude, and there was a nonsignificant trend towards baseline levels over 2 days at high altitude. $\mathrm{PA}-\mathrm{a}, \mathrm{O}_{2}$ did not change from low to high altitude, and showed a tendency to decrease during the stay at altitude $(\mathrm{p}<0.15)$. 
TABLE 1 Spirometric data and lung compliance

\begin{tabular}{|c|c|c|c|c|c|c|c|c|c|}
\hline \multirow[t]{2}{*}{ TLC \% pred } & All & 30 & $110 \pm 13$ & $111 \pm 14$ & $110 \pm 12$ & $110 \pm 14$ & 0.65 & & \\
\hline & AMS & 14 & $108 \pm 10$ & $106 \pm 10$ & $108 \pm 9$ & $107 \pm 10$ & & & \\
\hline \multirow[t]{2}{*}{ TLC L } & All & 30 & $7.6 \pm 1.1$ & $7.6 \pm 1.2$ & $7.6 \pm 1.1$ & $7.6 \pm 1.3$ & 0.81 & & \\
\hline & No AMS & 10 & $7.9 \pm 1.0$ & $8.1 \pm 1.2$ & $7.9 \pm 1.0$ & $8.2 \pm 1.4$ & 0.75 & 0.12 & 0.54 \\
\hline \multirow{2}{*}{ FVC \% pred } & No AMS & 10 & $115 \pm 16$ & $116 \pm 19$ & $117 \pm 20$ & $117 \pm 19$ & 0.10 & 0.55 & 0.62 \\
\hline & AMS & 14 & $110 \pm 11$ & $111 \pm 9$ & $112 \pm 8$ & $114 \pm 9$ & & & \\
\hline \multirow[t]{3}{*}{ FVC L } & All & 30 & $5.4 \pm 0.9$ & $5.6 \pm 0.8$ & $5.5 \pm 0.9$ & $5.5 \pm 0.9$ & 0.17 & & \\
\hline & No AMS & 10 & $5.6 \pm 0.7$ & $5.7 \pm 0.9$ & $5.7 \pm 0.9$ & $5.7 \pm 0.8$ & 0.10 & 0.50 & 0.66 \\
\hline & AMS & 14 & $5.3 \pm 1.0$ & $5.6 \pm 0.8$ & $5.4 \pm 0.9$ & $5.5 \pm 0.9$ & & & \\
\hline \multirow{2}{*}{$C \mathrm{~L}, \mathrm{st} \mathrm{L} \cdot \mathrm{kPa}^{-1}$} & No AMS & 10 & $3.6 \pm 1.6$ & $3.7 \pm 1.6$ & $3.9 \pm 1.8$ & & 0.13 & 0.29 & 0.98 \\
\hline & AMS & 14 & $3.2 \pm 0.8$ & $3.7 \pm 1.3$ & $3.7 \pm 1.4$ & & & & \\
\hline
\end{tabular}

Data are presented as mean \pm SD for all subjects without high-altitude pulmonary oedema (All) and the subgroups of subjects who suffered from acute mountain sickness (AMS) and who clearly remained healthy (No AMS). p-values were determined by ANOVA. There were no significant differences between low and high altitude and no group differences for any of the parameters. LA: low-altitude measurement (baseline); HA: high altitude measurement (HA1: $4 \mathrm{~h}$ after arrival; HA2: morning of day 2; and HA3: morning of day 3); pt: p-value for time; pgroup: p-value for group; pt x group: p-value for time $\times$ group; TLC: total lung capacity; \% pred: percentage of the predicted value; FVC: forced vital capacity; CV: closing volume; $\mathrm{CL}$,st: static lung compliance.

No changes in FVC, percentage predicted FVC, TLC and percentage predicted TLC were noted following inhalation of $200 \mu \mathrm{g}$ salbutamol at low and high altitude. Although salbutamol led to significant but small $(3-5 \%)$ increases in FEV1 and percentage predicted FEV1, and $8-18 \%$ increases in

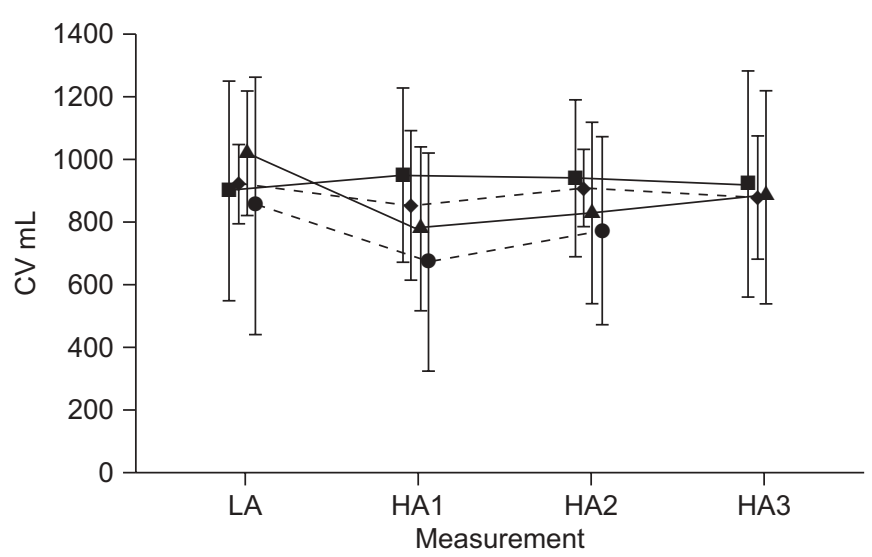

FIGURE 1. Closing volumes (CVs) over the study period for subjects with ( - ) and without $(\mathbf{\Lambda} ;-)$ acute mountain sickness (AMS), those with an uncertain diagnosis of AMS ( ; ----) and those who developed high-altitude pulmonary oedema (HAPE) during the study $(\bullet$; ----). Data are presented as mean \pm SD. In HAPE, at high-altitude measurement $(\mathrm{HA}) 3$, there was only one subject still not receiving therapy; therefore, no data point is shown. LA: low-altitude measurement; HA1: $4 \mathrm{~h}$ after arrival; HA2: morning of day 2; HA3: morning of day 3 . mid-expiratory flow rates, none of these met standard criteria for bronchodilator responsiveness. These changes were of the same magnitude at low and high altitude (fig. 2). Accordingly, Reff and sRaw decreased significantly with salbutamol $(p<0.01)$. The effect of salbutamol was of the same magnitude in all subjects, independent of the presence of AMS or HAPE.

\section{Comparison between subjects with and without AMS}

Subjects with AMS exhibited lower Reff and sRaw than subjects without AMS at HA2 and HA3 (table 2). Furthermore, subjects with AMS showed a nonsignificant trend towards smaller lung volumes (table 1), lower $\mathrm{Sa}_{1} \mathrm{O}_{2}$ and higher $\mathrm{PA}-\mathrm{a}, \mathrm{O}_{2}$ (table 3) at HA2 and HA3 compared to those without AMS. The differences were, however, nonsignificant. All other parameters measured in the present study were almost identical between subjects with and without AMS.

\section{Findings in HAPE}

HAPE occurred in the morning of HA2 in two subjects, during the night between HA2 and HA3 in one subject and in the morning of HA3 in another subject. Two subjects showed alveolar oedema in two quadrants and the other two in one quadrant of the lung. The mean radiographic score [28] was 7.8 3.9. A further decrease in $\mathrm{Sa}_{1} \mathrm{O}_{2}$ and an increase in $P \mathrm{~A}-\mathrm{a}_{1} \mathrm{O}_{2}$ and $D \mathrm{~L}, \mathrm{CO} /(V \mathrm{~A}$ demonstrated impaired gas exchange. The slight decrease in FVC, CV and lung compliance compared to measurements obtained at HA1, prior to the development of HAPE, are also suggestive of increased extravascular lung water at the time of diagnosis of HAPE (table 4). 


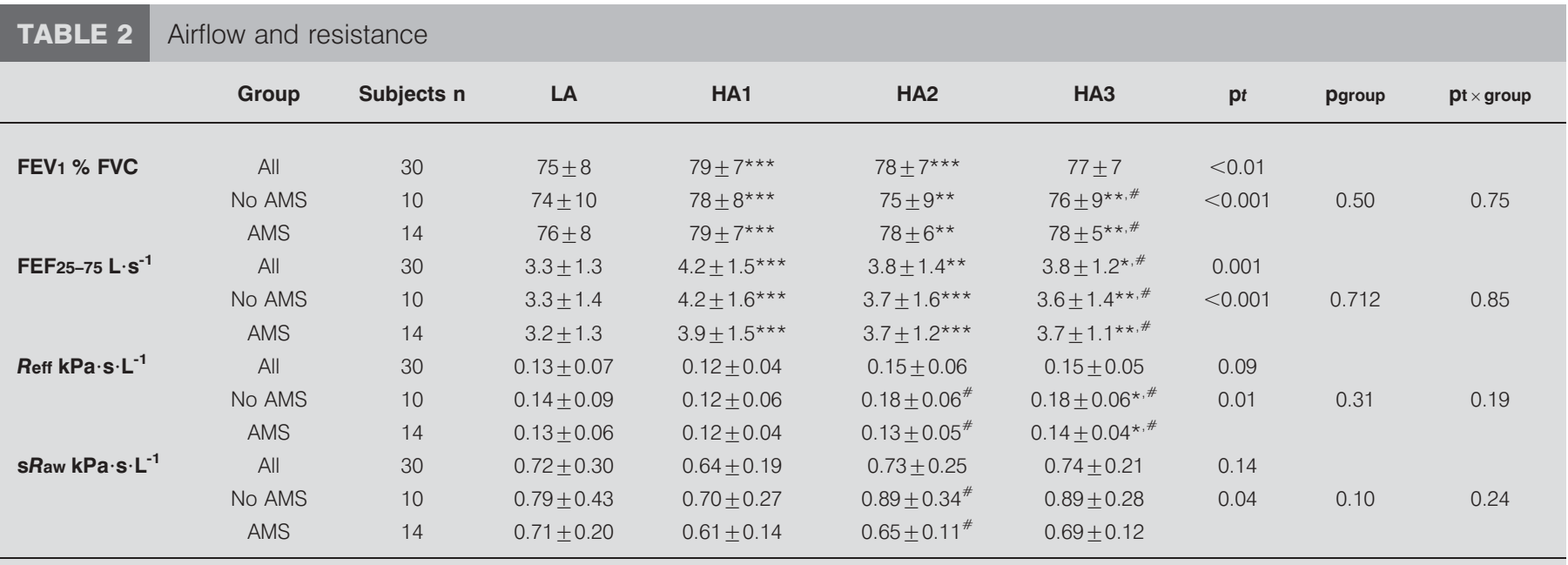

Data are presented as mean \pm SD for all subjects without high-altitude pulmonary oedema (All) and the subgroups of subjects who suffered from acute mountain sickness (AMS) and who clearly remained healthy (No AMS). p-values were determined by ANOVA. There were no significant differences between HA2 and HA3. LA: Iow-altitude measurement (baseline); HA: high altitude measurement (HA1: $4 \mathrm{~h}$ after arrival; HA2: morning of day 2; and HA3: morning of day 3); pt: p-value for time; pgroup: p-value for group; pt x group: $p$-value for time $\times$ group; FEV1: forced expiratory volume in $1 \mathrm{~s}$; FVC: forced vital capacity; FEF25-75: forced mid-expiratory flow (when 25-75\% of FVC has been exhaled); Reff: effective airway resistance; sRaw: total specific airway resistance. ${ }^{*}: p<0.05 ;{ }^{* *}: p<0.01 ;{ }^{* \star}: p<0.001$ versus LA; ${ }^{*}: p<0.05$ versus HA1.

\section{DISCUSSION}

Comprehensive pulmonary function testing using body plethysmography performed at an altitude of 4,559 m showed no changes in TLC, FVC, bronchodilator responsiveness, lung compliance and $\mathrm{CV}$, whereas parameters of airflow increased compared with baseline values obtained near sea level. The development of AMS had no impact on these measurements. In summary, no evidence was found on comprehensive pulmonary function testing suggestive of pulmonary interstitial fluid accumulation in non-acclimatised mountaineers with and without AMS within the first 2 days after rapid ascent to high altitude. In four subjects with early mild HAPE, small changes were found in several parameters consistent with increased lung water accumulation.

\section{Lung volumes}

The finding of unchanged lung volumes (TLC and FVC) in all subjects irrespective of AMS is in accordance with three other studies [13, 31, 32], but at variance with multiple previous studies showing a significant reduction in FVC following ascent to altitudes of $>4,000 \mathrm{~m}[4,6-12,33,34]$. Differences in statistical power, methodology, subject selection, ascent or time of examination may account for the discrepancies between studies. These factors are discussed in more detail below.

\section{TABLE 3 Gas exchange}

\begin{tabular}{|c|c|c|c|c|c|c|c|c|c|}
\hline & Group & Subjects n & LA & HA1 & HA2 & HA3 & $\mathrm{pt}$ & pgroup & pt $\times$ group \\
\hline \multirow[t]{2}{*}{$\mathrm{Sa}, \mathrm{O}_{2} \%$} & All & 30 & $98 \pm 1$ & $72 \pm 6^{\star \star \star}$ & $77 \pm 4^{\star \star \star, \# \# \#}$ & $80 \pm 5^{\star \star \star, \# \# \#, ~}$ & $<0.001$ & & \\
\hline & AMS & 14 & $98 \pm 1$ & $72 \pm 5^{\star \star \star}$ & $76 \pm 5^{\star \star \star \star \# ~}$ & $79 \pm 6^{\star \star \star . \# \# \#}$ & & & \\
\hline $\begin{array}{l}D \mathrm{~L}, \mathrm{CO} / \mathrm{VA}_{\mathrm{A}} \\
\quad \mathrm{mmol} \cdot \mathrm{min}^{-1} \cdot \mathrm{Pa}^{-1} \cdot \mathrm{L}^{-1}\end{array}$ & All & 30 & $1.71 \pm 0.17$ & $1.49 \pm 0.16^{\star \star \star}$ & $1.43 \pm 0.16^{\star \star \star \star * \# \# \# ~}$ & $1.41 \pm 0.17^{\star \star \star \star \# \# \# \# ~}$ & 0.001 & & \\
\hline \multirow[t]{3}{*}{${\mathrm{PA}-\mathrm{a}, \mathrm{O}_{2}} \mathrm{mmHg}^{+}$} & All & 30 & $10.5 \pm 8.4$ & $10.8 \pm 3.4$ & $9.0 \pm 4.1$ & $7.0 \pm 3.2$ & 0.15 & & \\
\hline & No AMS & 10 & $11.9 \pm 9.3$ & $10.8 \pm 3.8$ & $6.8 \pm 3.4$ & $5.7 \pm 2.1$ & 0.20 & 0.62 & 0.54 \\
\hline & AMS & 14 & $11.7 \pm 8.5$ & $10.7 \pm 3.7$ & $10.2 \pm 4.3$ & $8.0 \pm 3.4$ & & & \\
\hline
\end{tabular}

Data are presented as mean \pm SD for all subjects without high-altitude pulmonary oedema (All) and the subgroups of subjects who suffered from acute mountain sickness (AMS) and who clearly remained healthy (No AMS). p-values were determined by ANOVA. There were no significant group differences. LA: low-altitude measurement (baseline); HA: high altitude measurement (HA1: $4 \mathrm{~h}$ after arrival; HA2: morning of day 2; and HA3: morning of day 3); pt: p-value for time; pgroup: $p$-value for group; pt $\times$ group: $\mathrm{p}$-value for time $\times$ group; $\mathrm{Sa}, \mathrm{O}_{2}$ : arterial oxygen saturation; $\mathrm{DL}, \mathrm{CO}$ : diffusing capacity of the lung for carbon monoxide; $V_{\mathrm{A}}$ : alveolar volume; $\mathrm{PA}_{\mathrm{A}-\mathrm{a}} \mathrm{O}_{2}$ : alveolararterial oxygen tension difference. ${ }^{+}$: calculated from arterial blood samples at LA, HA1 and HA2 and from arterialised capillary blood samples at HA3. ${ }^{* * *}$ : $\mathrm{p}<0.001$

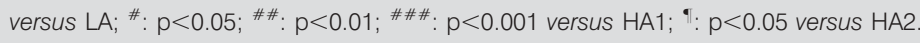



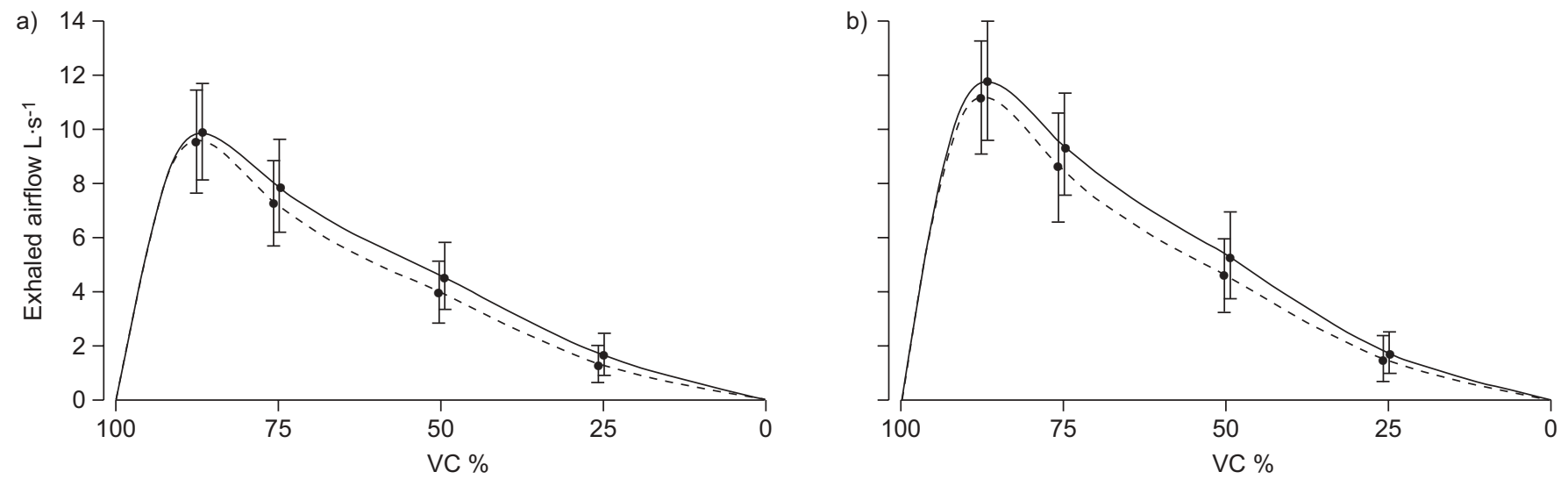

FIGURE 2. Mean flow-volume curve for the forced exhalation before (-----) and 10 min after ( - inhalative administration of 200 $\mu \mathrm{g}$ salbutamol at: a) low altitude; and b) the second day at 4,559 $\mathrm{m}$ (high altitude measurement 2). The curves show the mean $\pm \mathrm{SD}$ of all subjects without high-altitude pulmonary oedema ( $\mathrm{n}=30$ ). $\mathrm{VC}$ : vital capacity

Insufficient statistical power of the present study with regard to FVC is an unlikely explanation since the largest investigation, performed on 197 mountaineers at the same location in a similar setting, reported virtually unchanged FVC in subjects without clinical signs of HAPE [13]. Furthermore, seven studies $[4-9,12]$ reporting decreased FVC had 4-26 subjects, i.e. had less statistical power than the present study.

It is also unlikely that the use of body plethysmography and pneumotachography in the present study accounts for discrepancies with other investigations since GAUTIER et al. [5] used the same type of equipment and found a decrease in FVC. The specified range of ambient pressures for the current equipment includes the altitude of $4,559 \mathrm{~m}$, at which it was used. Measurements using both the body plethysmograph and the pneumotachograph are based on pressure differences and,

\begin{tabular}{|c|c|c|c|c|}
\hline \multirow[t]{2}{*}{ TABLE 4} & \multicolumn{4}{|c|}{$\begin{array}{l}\text { Subjects developing high-altitude pulmonary } \\
\text { oedema (HAPE) }\end{array}$} \\
\hline & & LA & HA1 & $\begin{array}{l}\text { At HAPE } \\
\text { diagnosis }\end{array}$ \\
\hline TLC L & & $7.6 \pm 1.9$ & $7.8 \pm 2.1$ & $7.6 \pm 2.0$ \\
\hline TLC \% pred & & $112 \pm 8$ & $115 \pm 8$ & $113 \pm 8$ \\
\hline FVC L & & $5.8 \pm 1.6$ & $5.7 \pm 1.5$ & $5.5 \pm 1.3$ \\
\hline FVC \% pred & & $127 \pm 10$ & $126 \pm 12$ & $121 \pm 9$ \\
\hline FEV 1 \% FVC & & $75 \pm 5$ & $78 \pm 6$ & $77 \pm 8$ \\
\hline CV L & & $0.85 \pm 0.41$ & $0.67 \pm 0.35$ & $0.78 \pm 0.29$ \\
\hline $\mathrm{Sa}, \mathrm{O}_{2} \%$ & & $98 \pm 2$ & $67 \pm 7$ & $48 \pm 7$ \\
\hline${\mathrm{PA}-\mathrm{a}, \mathrm{O}_{2}}_{2} \mathrm{mmH}$ & & $6.3 \pm 5.9$ & $8.9 \pm 6.5$ & $15.9 \pm 3.7$ \\
\hline $\begin{array}{l}D \mathrm{~L}, \mathrm{Co} / V_{A} \\
\mathrm{mmol} \cdot \mathrm{min}^{-1}\end{array}$ & $\mathrm{~Pa}^{-1} \cdot \mathrm{L}^{-1}$ & $1.7 \pm 0.2$ & $1.9 \pm 0.3$ & $1.6 \pm 0.3$ \\
\hline$C L, s t L \cdot k^{-1}$ & & $2.7 \pm 0.5$ & $3.7 \pm 1.2$ & $3.2 \pm 0.8$ \\
\hline
\end{tabular}

LA: low-altitude measurement; HA1: high-altitude measurement $4 \mathrm{~h}$ after arrival at high altitude; TLC: total lung capacity; \% pred: percentage of the predicted value; FVC: forced vital capacity; FEV1: forced expiratory volume in $1 \mathrm{~s}$; CV: closing volume; $\mathrm{Sa}_{2} \mathrm{O}_{2}$ : arterial oxygen saturation; $\mathrm{PA}-\mathrm{a}_{1} \mathrm{O}_{2}$ : alveolar-arterial oxygen tension difference; $D \mathrm{~L}, \mathrm{CO}$ : diffusing capacity of the lung for carbon monoxide; VA: alveolar volume; CL,st: static lung compliance. therefore, independent of absolute pressure over a wide range. Calibration of both devices was performed regularly before a subject was measured. Control measurements using the pneumotachograph following calibration always showed the exact volume of the calibration syringe $(3 \mathrm{~L})$ at various flow rates. Therefore, the possibility has been excluded that erroneous measurements account for the finding of unchanged lung volumes at $4,559 \mathrm{~m}$.

Since measurements of FVC and TLC are effort-dependent, slight differences in the level of effort could contribute to discrepancies between studies. Strenuous exercise preceding the measurements and symptoms of AMS might affect subjects if they are not acclimatised to the altitude, and could result in slightly reduced effort by the subject. The data reported by CoGo et al. [8] fit well with this assumption. In the same setting in which the present study was performed, this group found decreased lung volumes on day 1 after arrival, which returned to baseline levels or even greater on the following 3 days [8]. Similarly, the reduction in FVC on day 1 at 5,300 m [11] was twice as high as that on day 3 [35]. Two studies that report predicted values [12], or data that permit calculation of predicted values [7], and also show a reduction in FVC of 8 and $7 \%$ report vital capacities of $87-96 \%$ pred. In the light of these discrepancies, careful attention was paid to providing the greatest encouragement of maximal efforts. A mean FVC of $115-117 \%$ pred and TLC of $110-111 \%$ pred suggested that, indeed, maximal efforts were obtained at each examination. Some of the previous studies may have paid less attention to this issue. Therefore, differences in the level of effort could be a factor contributing to discrepant findings between studies.

The high FVC and TLC measured in the present study may suggest that a selected population, resistant to acute highaltitude illnesses, was examined since large lung volumes have been reported in HAPE-resistant controls [36-39]. Although there was no selection on recruitment, it cannot be excluded that the present study population had larger lung volumes by chance and that the subjects might have been more resistant to the development of early interstitial pulmonary oedema due to the supranormal lung volumes, which could explain the lack of changes observed in the present study. However, this notion is not supported by the fact that subjects who developed HAPE 
during the study exhibited even larger lung volumes than the other groups. Furthermore, no correlation was found between lung size and changes in spirometric parameters, $\mathrm{CV}$ or compliance. Training status, which was not assessed, is also an unlikely explanation since (endurance) training has no influence on lung volumes [40, 41].

Different rates or modes of ascent and time of exposure at altitude could also contribute to discrepancies between studies. In addition to having an impact on effort through fatigue, as discussed above, rapid ascent and the associated strenuous exercise at altitude could cause interstitial pulmonary oedema $[16,42]$, whereas the effects of altitude on interstitial fluid accumulation and lung volumes are less clear. A study reporting an increase in lung volumes, approaching sea level values over time at altitude [8], does not help to explain why no decrease was found on the first and second day at high altitude.

\section{Diffusing capacity}

$D \mathrm{~L}, \mathrm{CO} / V \mathrm{~A}$ is a sensitive, although nonspecific, measure of pulmonary impairment in many diseases, including those associated with extravascular lung water accumulation. As a result of mild elevations in pulmonary arterial pressure and cardiac output with acute hypoxia at high altitude, there is pulmonary vascular recruitment that increases $D \mathrm{~L}, \mathrm{CO} / V \mathrm{~A}$ [36]. It was found that the $D \mathrm{~L}, \mathrm{CO} / V \mathrm{~A}$ at high altitude was equally elevated in subjects with and without AMS, and that there was no correlation between AMS scores and changes in $D \mathrm{~L}, \mathrm{CO} / V \mathrm{~A}$. These improvements in $D \mathrm{~L}, \mathrm{CO} / V \mathrm{~A}$ are consistent with the other measures of lung function in providing no evidence to support the presence of interstitial oedema. The only other study that examined $D \mathrm{~L}, \mathrm{CO} / V \mathrm{~A}$ in subjects with AMS at $4,700 \mathrm{~m}$ reported that, on average, $D \mathrm{~L}, \mathrm{CO} / V \mathrm{~A}$ did not rise, and, across all subjects, there was an inverse correlation of AMS scores with changes in $D \mathrm{~L}, \mathrm{CO} / V \mathrm{~A}$ [29]. The reductions in $D \mathrm{~L}, \mathrm{CO} / V \mathrm{~A}$ were interpreted as evidence for interstitial oedema in those with moderate-to-severe AMS. We have no ready explanation for the marked difference between the present study and that of GE et al. [31], except that we studied lowland Caucasian subjects climbing from very low altitude to $4,559 \mathrm{~m}$ over 2 days, in contrast to the latter study, in which Han Chinese subjects already acclimated to $2,700 \mathrm{~m}$ drove by motor vehicle to $4,700 \mathrm{~m}$ over 3 days. How these differences in baseline altitude, ascent rate, total elevation gain, smoking habits, salt intake and ethnicity might explain the discrepancy between the studies is not clear. Greater insight into these differences with AMS might be gained by studying the membrane and capillary blood volume components of $D \mathrm{~L}, \mathrm{CO} / V \mathrm{~A}$, using either nitric oxide or several levels of inspired oxygen.

\section{Airflow rates}

FEV1 and maximal mid-expiratory flow (when 25-75\% of FVC remains to be exhaled) were increased significantly in all examinations at high altitude, with the highest values on day 1 , whereas Reff and sRaw did not change significantly. These findings can be explained by reduced air density, and are in agreement with the results of previous studies [5, 13, 33, 43]. Despite normal Reff and sRaw and FEV1, both were improved somewhat by salbutamol, but this improvement was below that considered to be a significant bronchodilator response and was independent of altitude and preceding exercise. This finding demonstrates that cold air, hypocapnia or exercise during ascent did not cause bronchoconstriction.

\section{Closing volume}

Two studies later reported an increase in CV at the location of the present study after ascent rates comparable to those of the present study $[12,13]$. Both groups interpreted increased CV as indicative of interstitial pulmonary fluid accumulation and subclinical HAPE. It was not possible to reproduce the finding of increased $\mathrm{CV}$, and the present measurements of $\mathrm{CV}$ were $\sim 60 \%$ higher than those previously reported by these groups. Although differences in methodology, discussed earlier and below, might account for these discrepancies, we wish to point out that, in addition to unchanged CV, all other measurements performed in the present study, such as lung volumes, airflow, lung compliance, $\mathrm{DL}, \mathrm{CO}$ at rest and $\mathrm{PA}-\mathrm{a}, \mathrm{O}_{2}$, do not provide any evidence for the hypothesis that acute exposure to $4,559 \mathrm{~m}$ causes interstitial pulmonary fluid accumulation.

SENN et al. [12] and the present study measured CV using the single-breath nitrogen washout method, for which a slow and complete exhalation at a rate of $\sim 0.5 \mathrm{~L} \cdot \mathrm{min}^{-1}$ is crucial [27]. Both groups used different commercially available devices that help subjects to control the rate of exhalation by means of visual feedback. The system used by SENN et al. [12] employs a valve with a considerably smaller diameter than that of the device used in the present study. A smaller valve diameter has the advantage of more easily holding the expiratory flow constant, by superimposing a small resistance during exhalation. This results in a slight positive end-expiratory pressure, which keeps the small airways open to somewhat lower lung volumes and decreases air trapping [44], resulting in lower measured CVs. With the reduced air density at high altitude, this resistance decreases and may account for an increase in CV. The results of GRAY et al. [45], who reported the first CV measurements obtained at high altitude, are in accordance with this hypothesis. They also used a method without increased expiratory resistance and found no changes in $\mathrm{CV}$ at $5,300 \mathrm{~m}$ in 12 subjects. It is important to note, however, that several of their subjects were on acetazolamide and measurements were performed on day 7. Finally, maximum verbal encouragement to achieve complete exhalation may contribute to the higher CVs measured at both altitudes in the present study.

As pointed out above, the present study was designed to have sufficient statistical power for the detection of changes in $\mathrm{CV}$ reported by CREMONA et al. [13], although the power of the latter study could not be approached. Furthermore, discrepant results, compared with the studies of CREMONA et al. [13] and SENN et al. [12], cannot be attributed to different ascent rates since they were very similar or identical in all three investigations. The time of examination may, however, explain the apparent difference from the results of CREMONA et al. [13], who measured CV $1 \mathrm{~h}$ after arrival at the Capanna Regina Margherita, whereas the present measurements were performed 4, 20 and $44 \mathrm{~h}$ after arrival. It is conceivable that strenuous exercise at altitudes of 3,611-4,559 m causes mild pulmonary oedema $[16,46]$ that resolves rapidly at rest and may thus no longer be detectable after $4 \mathrm{~h}$, and particularly 20 
or $44 \mathrm{~h}$. In addition, CREMONA et al. [13] determined CV using recordings of the intrabreath $\mathrm{R}$. This method is completely different from the classical single-breath nitrogen washout method and has never been tested in the same subjects to demonstrate equivalence. It is, therefore, not known whether CVs determined by these different methods are directly comparable. They may be differentially affected by conditions unique to high altitude, such as a different span of regional $P A, O_{2}$ and $P A, C_{2}$ compared to sea level, and, in the case of the single-breath nitrogen washout method, the influence of a sudden rise in oxygen tension throughout the lung.

\section{Acute mountain sickness}

In order to permit a clear distinction between individuals who felt well and those who had AMS, six subjects with questionable scores were excluded from the present analysis. There were no significant differences in lung volumes, airflow rates, $\mathrm{CV}$ and $D \mathrm{~L}, \mathrm{CO} / V \mathrm{~A}$ at rest between mountaineers with and without AMS, except for a significantly lower Reff plus sRaw on days 2 and 3 at 4,559 $\mathrm{m}$ in those with AMS. This difference might be attributed to higher plasma levels of adrenalin in AMS, a finding that has been reported from a similar study at the same location [21]. In accordance with previous studies [37], a tendency to lower $\mathrm{PA}-\mathrm{a}, \mathrm{O}_{2}$ and higher $\mathrm{Sa}_{1} \mathrm{O}_{2}$ on the second and third day at altitude was observed in all subjects with somewhat higher $\mathrm{PA}-\mathrm{a}, \mathrm{O}_{2}$ and lower $\mathrm{Sa}_{2} \mathrm{O}_{2}$ in the AMS group. Based on these data, we conclude that standard clinical pulmonary function testing might not be sensitive enough to detect the small degree of interstitial fluid accumulation that might cause impaired gas exchange in AMS. One possibility that has not been tested is whether AMS leads to impaired regulation of local regional ventilation and perfusion, such as a change in the degree of hypoxic pulmonary vasoconstriction. We also need to point out that body temperature was not measured when blood gas analysis was performed. AMS is associated with a slight increase in body temperature of $\sim 0.4^{\circ} \mathrm{C}$ [47], which leads to an overestimation of $\mathrm{PA}-\mathrm{a}, \mathrm{O}_{2}$ by $\sim 3 \%$. Thus impairment of gas exchange and the postulated underlying interstitial pulmonary oedema may be minimal.

\section{High-altitude pulmonary oedema}

Four subjects developed HAPE during the study. Their data at LA, HA1 and the time of HAPE development are shown in table 4. Two showed alveolar oedema in one and two alveolar oedema in two lung quadrants on the radiographs [28]. $\mathrm{Sa}_{2} \mathrm{O}_{2}$ was decreased and $\mathrm{PA}-\mathrm{a}, \mathrm{O}_{2}$ increased in these patients. FVC, $D \mathrm{~L}, \mathrm{CO} / V \mathrm{~A}$ and lung compliance were all slightly decreased and $\mathrm{CV}$ increased somewhat in the HAPE patients. These changes are compatible with an increase in lung water, but are rather small compared with the degree of deterioration in gas exchange and the extent of the radiographic findings. The discrepancy between alterations in gas exchange or on radiographs and changes in lung function demonstrate that the latter are not sensitive methods for the detection of mild interstitial lung oedema or subclinical HAPE rather than the overt disease.

\section{Conclusion}

In summary, we found no evidence for interstitial pulmonary oedema using body plethysmography and measurements of $\mathrm{CV}$ and lung compliance in 30 mountaineers with and without
AMS over 2 days at $4,559 \mathrm{~m}$ following rapid ascent to this altitude. Data obtained in mountaineers with early mild HAPE suggest, moreover, that these methods are not very sensitive for the detection of interstitial fluid accumulation in the lungs.

\section{STATEMENT OF INTEREST}

Statements of interest for C. Dehnert and P. Bärtsch and the study itself can be found at www.erj.ersjournals.com/misc/statements.dtl

\section{ACKNOWLEDGEMENTS}

The authors thank the study participants; the hut keepers and the Varallo Section of the Italian Alpine Club (Milan, Italy) for providing an excellent research facility at the Capanna Regina Margherita; G. Robotti and S. Greppi (both Dept of Radiology, Lugano Regional Hospital, Lugano, Switzerland) and C. Imesch (Dept of Radiology, University Hospital Inselspital, Berne, Switzerland) for performing chest radiography at the Capanna Regina Margherita; VIASYS Healthcare for financial and technical support for body plethysmography; and ZAN Messgeräte for technical support with the measurements of closing volume.

\section{REFERENCES}

1 Rahn H, Hammond D. Vital capacity at reduced barometric pressure. J Appl Physiol 1952; 4: 715-724.

2 Tenney SM, Rahn H, Stroud RC, et al. Adoption to high altitude: changes in lung volumes during the first seven days at Mt. Evans, Colorado. J Appl Physiol 1953; 5: 607-613.

3 Anholm JD, Houston CS, Hyers TM. The relationship between acute mountain sickness and pulmonary ventilation at 2,835 meters (9,300 ft). Chest 1979; 75: 33-36.

4 Jaeger JJ, Sylvester JT, Cymerman A, et al. Evidence for increased intrathoracic fluid volume in man at high altitude. J Appl Physiol 1979; 47: 670-676.

5 Gautier H, Peslin R, Grassino A, et al. Mechanical properties of the lungs during acclimatization to altitude. J Appl Physiol 1982; 52: 1407-1415.

6 Selland MA, Stelzner TJ, Stevens T, et al. Pulmonary function and hypoxic ventilatory response in subjects susceptible to highaltitude pulmonary edema. Chest 1993; 103: 111-116.

7 Basu CK, Selvamurthy W, Bhaumick G, et al. Respiratory changes during initial days of acclimatization to increasing altitudes. Aviat Space Environ Med 1996; 67: 40-45.

8 Cogo A, Legnani D, Allegra L. Respiratory function at different altitudes. Respiration 1997; 64: 416-421.

9 Hashimoto F, McWilliams B, Qualls C. Pulmonary ventilatory function decreases in proportion to increasing altitude. Wilderness Environ Med 1997; 8: 214-217.

10 Pollard AJ, Barry PW, Mason NP, et al. Hypoxia, hypocapnia and spirometry at altitude. Clin Sci (Lond) 1997; 92: 593-598.

11 Mason NP, Petersen M, Melot C, et al. Serial changes in nasal potential difference and lung electrical impedance tomography at high altitude. J Appl Physiol 2003; 94: 2043-2050.

12 Senn O, Clarenbach CF, Fischler M, et al. Do changes in lung function predict high-altitude pulmonary edema at an early stage? Med Sci Sports Exerc 2006; 38: 1565-1570.

13 Cremona G, Asnaghi R, Baderna $P$, et al. Pulmonary extravascular fluid accumulation in recreational climbers: a prospective study. Lancet 2002; 359: 303-309.

14 Caillaud C, Serre-Cousine O, Anselme F, et al. Computerized tomography and pulmonary diffusing capacity in highly trained athletes after performing a triathlon. J Appl Physiol 1995; 79: 12261232.

15 Hopkins SR, Schoene RB, Henderson WR, et al. Intense exercise impairs the integrity of the pulmonary blood-gas barrier in elite athletes. Am J Respir Crit Care Med 1997; 155: 1090-1094. 
16 Anholm JD, Milne EN, Stark P, et al. Radiographic evidence of interstitial pulmonary edema after exercise at altitude. J Appl Physiol 1999; 86: 503-509.

17 Wilber RL, Rundell KW, Szmedra L, et al. Incidence of exerciseinduced bronchospasm in Olympic winter sport athletes. Med Sci Sports Exerc 2000; 32: 732-737.

18 Storms WW. Exercise-induced asthma: diagnosis and treatment for the recreational or elite athlete. Med Sci Sports Exerc 1999; 31: Suppl., S33-S38.

19 Larsson K, Ohlsen P, Larsson L, et al. High prevalence of asthma in cross country skiers. BMJ 1993; 307: 1326-1329.

20 O'Cain CF, Hensley MJ, McFadden ER Jr, et al. Pattern and mechanism of airway response to hypocapnia in normal subjects. J Appl Physiol 1979; 47: 8-12.

21 Bärtsch $\mathrm{P}$, Shaw S, Franciolli M, et al. Atrial natriuretic peptide in acute mountain sickness. J Appl Physiol 1988; 65: 1929-1937.

22 Hohenhaus E, Niroomand F, Goerre S, et al. Nifedipine does not prevent acute mountain sickness. Am J Respir Crit Care Med 1994; 150: 857-860.

23 Hackett PH, Roach RC. High-altitude illness. N Engl J Med 2001; 345: 107-114.

24 Berger MM, Dehnert C, Bailey DM, et al. Transpulmonary plasma ET-1 and nitrite differences in high altitude pulmonary hypertension. High Alt Med Biol 2009; 10: 17-24.

25 Anon, Standardization of spirometry, 1994 update. American Thoracic Society. Am J Respir Crit Care Med 1995; 152: 1107-1136.

26 Macintyre N, Crapo RO, Viegi G, et al. Standardisation of the single-breath determination of carbon monoxide uptake in the lung. Eur Respir J 2005; 26: 720-735.

27 West JB. Ventilation. In: West JB., ed. Pulmonary Pathophysiology - The Essentials. $3^{\text {rd }}$ edn. Baltimore, MD, Williams and Wilkins, 1987; pp. 1-18.

28 Vock P, Fretz C, Franciolli M, et al. High-altitude pulmonary edema: findings at high-altitude chest radiography and physical examination. Radiology 1989; 170: 661-666.

29 Roach RC, Bärtsch P, Hackett PH, et al. The Lake Louise acute mountain sickness scoring system. In: Sutton JR, Houston CS, Coates A, eds. Hypoxia and Molecular Medicine. Burlington, VT, Queen City Printers, Inc., 1993; pp. 272-274.

30 Sampson JB, Cymerman A, Burse RL, et al. Procedures for the measurement of acute mountain sickness. Aviat Space Environ Med 1983; 54: 1063-1073.

31 Ge RL, Matsuzawa Y, Takeoka M, et al. Low pulmonary diffusing capacity in subjects with acute mountain sickness. Chest 1997; 111: 58-64.
32 Mansell A, Powles A, Sutton J. Changes in pulmonary PV characteristics of human subjects at an altitude of 5,366 m. J Appl Physiol 1980; 49: 79-83.

33 Welsh $\mathrm{CH}$, Wagner PD, Reeves JT, et al. Operation Everest. II spirometric and radiographic changes in acclimatized humans at simulated high altitudes. Am Rev Respir Dis 1993; 147: 1239-1244.

34 Deboeck G, Moraine JJ, Naeije R. Respiratory muscle strength may explain hypoxia-induced decrease in vital capacity. Med Sci Sports Exerc 2005; 37: 754-758.

35 Pollard AJ, Mason NP, Barry PW, et al. Effect of altitude on spirometric parameters and the performance of peak flow meters. Thorax 1996; 51: 175-178.

36 Eldridge MW, Podolsky A, Richardson RS, et al. Pulmonary hemodynamic response to exercise in subjects with prior highaltitude pulmonary edema. J Appl Physiol 1996; 81: 911-921.

37 Hohenhaus E, Paul A, McCullough RE, et al. Ventilatory and pulmonary vascular response to hypoxia and susceptibility to high altitude pulmonary oedema. Eur Respir J 1995; 8: 1825-1833.

38 Steinacker JM, Tobias P, Menold E, et al. Lung diffusing capacity and exercise in subjects with previous high altitude pulmonary oedema. Eur Respir J 1998; 11: 643-650.

39 Viswanathan R, Jain SK, Subramanian S, et al. Pulmonary edema of high altitude. II. Clinical, aerohemodynamic, and biochemical studies in a group with history of pulmonary edema of high altitude. Am Rev Respir Dis 1969; 100: 334-341.

40 Mahler DA, Moritz ED, Loke J. Ventilatory responses at rest and during exercise in marathon runners. J Appl Physiol 1982; 52: 388-392.

41 Wagner PD. Why doesn't exercise grow the lungs when other factors do? Exerc Sport Sci Rev 2005; 33: 3-8.

42 Hopkins SR, Gavin TP, Siafakas NM, et al. Effect of prolonged, heavy exercise on pulmonary gas exchange in athletes. $J$ Appl Physiol 1998; 85: 1523-1532.

43 Forte VA Jr, Leith DE, Muza SR, et al. Ventilatory capacities at sea level and high altitude. Aviat Space Environ Med 1997; 68: 488-493.

44 Harken AH, O'Connor NE. The influence of clinically undetectable pulmonary edema on small airway closure in the dog. Ann Surg 1976; 184: 183-188.

45 Gray GW, Rennie ID, Houston CS, et al. Phase IV volume of the single-breath nitrogen washout curve on exposure to altitude. J Appl Physiol 1973; 35: 227-230.

46 Hammond MD, Gale GE, Kapitan KS, et al. Pulmonary gas exchange in humans during exercise at sea level. J Appl Physiol 1986; 60: 1590-1598.

47 Maggiorini M, Bärtsch P, Oelz O. Association between raised body temperature and acute mountain sickness: cross sectional study. BMJ 1997; 315: 403-404. 